\title{
Expression of transforming growth factor $\beta$ and matrix metalloproteinases in the aqueous humor of patients with congenital ectopia lentis
}

\author{
QIANZHONG CAO ${ }^{1 *}$, BING XIAO $^{1 *}$, GUANGMING JIN $^{1 *}$, JIANQIANG LIN $^{1}$, \\ YIYAO WANG ${ }^{1}$, CHARLOTTE AIMEE YOUNG ${ }^{2}$, JUNXIONG LIN $^{1}$, YIJING ZHOU ${ }^{1}$, \\ BO ZHANG ${ }^{1}$, MINGZHE CAO ${ }^{1}$, KAILI WU ${ }^{1}$ and DANYING ZHENG ${ }^{1}$
}

${ }^{1}$ State Key Laboratory of Ophthalmology, Zhongshan Ophthalmic Center, Sun Yat-Sen University, Guangzhou,
Guangdong 510060, P.R. China; ${ }^{2}$ Department of Ophthalmology, University of California, San Francisco, CA 94115, USA

Received August 19, 2018; Accepted April 25, 2019

DOI: $10.3892 / \mathrm{mmr} .2019 .10287$

\begin{abstract}
It is well known that transforming growth factor $\beta$ (TGF $\beta)$, which is able to stimulate multiple intracellular signaling pathways, exerts an important role in Marfan syndrome, although the effects of TGF $\beta$ on congenital ectopia lentis (CEL) have yet to be fully elucidated. In the present study, the expression levels of TGF $\beta$ and matrix metalloproteinases (MMPs) were investigated in the aqueous humor of patients with ectopic lentis who differed in terms of the severity of the disease. A total of 17 CEL patients with 21 eyes (aged 12.76 \pm 9.37 years) and 12 congenital cataract (CC) patients with 17 eyes (aged 6.82 \pm 9.18 years) were randomized in the present study. The levels of active TGF $\beta$ and MMPs in the aqueous humor were analyzed with Luminex xMAP technology by using commercially available Bio-Plex Pro $^{\text {TM }}$ Human MMP and TGF $\beta$ assays. The distance from the lens edge to the pupil edge and the white to white corneal diameter (i.e. the horizontal distance between the borders of the corneal limbus) were measured, and the ratio was calculated as the degree of lens dislocation. The association between TGF $\beta$ and MMP levels and the degree of lens dislocation was analyzed using Spearman's correlation test. Compared with the patients with CC, the level of TGF 32 in the patients with CEL was increased significantly. Specifically, the level of TGF $\beta 2$ in the CEL patients was $855.19 \mathrm{pg} / \mathrm{ml}(744.33,1,009.24)$, whereas it was $557.08(438.24,692.71) \mathrm{pg} / \mathrm{ml}$ in the CC patients $(\mathrm{P}<0.001)$.
\end{abstract}

Correspondence to: Professor Danying Zheng, State Key Laboratory of Ophthalmology, Zhongshan Ophthalmic Center, Sun Yat-Sen University, 54 Xianlie Nan Lu, Guangzhou, Guangdong 510060, P.R. China

E-mail: zhengdyy@163.com

*Contributed equally

Key words: transforming growth factor $\beta$, matrix metalloproteinase, congenital ectopia lentis, aqueous humor
In addition, it was noted that the levels of MMP- 2 and -10 in the aqueous humor of the patients with CEL were higher compared with those in the CC patients, although this increase did not reach the level of statistical significance. Notably, the levels of MMP-8 and -9 in the aqueous humor of patients with CEL were significantly lower compared with those in the CC patients $(\mathrm{P}=0.014$ and $\mathrm{P}=0.002$, respectively). Furthermore, a marginal correlation was identified between the severity of ectopic lentis and the levels of TGF 32 in the aqueous humor $\left(r^{2}=0.379 ; P=0.003\right)$ of the patients with CEL. Taken together, these results demonstrated that a significant correlation existed between high levels of aqueous humor TGF $\beta 2$ and the severity of ectopia lentis in patients with CEL. In addition, aqueous humor TGF $\beta 2$ levels in the CEL patients were significantly higher compared with those in CC patients.

\section{Introduction}

Congenital ectopia lentis (CEL) occurs in a variety of genetic diseases, including Marfan syndrome (MFS), acromicric dysplasia, geleophysic dysplasia 2 and Weill Marchesani syndrome. Fibrillin-containing microfibrils are the major components of zonular fibers, and disruption of zonular fibers causes ectopia lentis. The fibrillin 1 (FBN1) gene, encoding fibrillin 1 protein, is generally identified as being mutated in the majority of the cases of ectopia lentis. Microfibrils in the extracellular matrix are predominantly composed of FBN1 protein, and serve an important role in incorporating elastin into elastic fibers. As a result, FBN1 mutations are associated with impairments in protein synthesis and secretion, leading subsequently to their improper incorporation into the connective tissue (1).

It has been well established that transforming growth factor $\beta(\mathrm{TGF} \beta)$ is a potent stimulator of inflammation, fibrosis and the activation of certain matrix metalloproteinases (MMPs), which serve multiple essential roles, including in fibrosis, proliferation and wound repair $(2,3)$. TGF $\beta 1, \beta 2$ and $\beta 3$ are crucial isoforms expressed in mammals that are able to bind to the same receptor to elicit their biological effects. TGF 32 , in particular, is essential in ocular physiological and pathological processes, and is predominantly localized in 
limbal epithelial cells and the ciliary body (4,5). In addition, activation of the TGF $\beta$ signaling pathways may accelerate the progression of aneurysms and encourage pneumothorax (collapsed lung) in MFS. Given what is currently known about TGF $\beta$, treatments based upon restricting TGF $\beta$ signaling are currently undergoing clinical trials $(6,7)$.

Isogai et al (8) reported that TGF $\beta$ produced by cells acts as a large latent complex that is able to bind to extracellular matrix (ECM) proteins, such as fibrillin 1. Current models have demonstrated that blockade of TGF $\beta$ by ECM chelating ligand leads to an inhibition of its activation, thus limiting the stimulation of its cell surface receptor. On the other hand, an elevation in the levels of TGF $\beta$ may exert its detrimental effects (with respect to MFS) through two distinct intracellular signaling pathways: The canonical and non-canonical signal transduction pathways (9-11).

Regarding the canonical signaling pathway, TGF $\beta$ and its receptor binding complex are able to significantly enhance Smad2 and/or Smad3 phosphorylation, and, once phosphorylated, these proteins cause the recruitment of Smad4, its translocation to the nucleus, and the transcription of Smad-dependent genes (12). On the other hand, TGF $\beta$ activates non-canonical pathways, including the MAPK and JNK signaling pathways, $\mathrm{p} 38$ and RhoA cascades, the first of which includes ERK (13-15).

In mouse models, blocking JNK leads to a reduction in the activity of MMPs, which serve an important role in MFS pathology, indicating that JNK might be a therapeutic target (16). In addition, inhibiting the p38 MAPK pathway leads to a suppression in the levels of the MMPs. Furthermore, ERK1/2 blockade was revealed to elevate the levels of MMP inhibitors on cell membranes (17). TGF $\beta$ increases the expression levels of elastase and numerous MMPs (18). As an elevated level of elastase is able to promote elastin degradation, and MMPs can invoke a major collapse in the elastic fibers, overexpression of these proteases is able to reduce connective tissue elasticity, thereby contributing to instability of the aortic wall. The association between TGF $\beta$ and MMP expression has been well elucidated in the MFS mouse model (19).

High concentrations of active TGF $\beta$ are able to activate multiple intracellular signaling pathways that are involved in the progression of MFS. However, the underlying mechanisms have yet to be properly elucidated. The aim of the present study was to investigate the expression levels of TGF $\beta$ and MMPs in the aqueous humor of patients with CEL and congenital cataracts (CC), and their potential correlation with the severity of ectopic lentis.

\section{Patients and methods}

Patients and samples. An observational study was conducted on 17 patients with CEL and 12 patients with CC. It was necessary that the patients who applied to Zhongshan Ophthalmic Center, Sun Yat-sen University of Medicine between January 2015 and December 2016 had been diagnosed with either CEL or CC. Inclusion criteria included the following: i) Diagnosed with CEL or CC, respectively; ii) patient aged between 1 and 32 years; and iii) patients in the CEL group had no other ocular diseases, such as CC or other congenital anterior segment malformations, with the exception of the abnormal lens

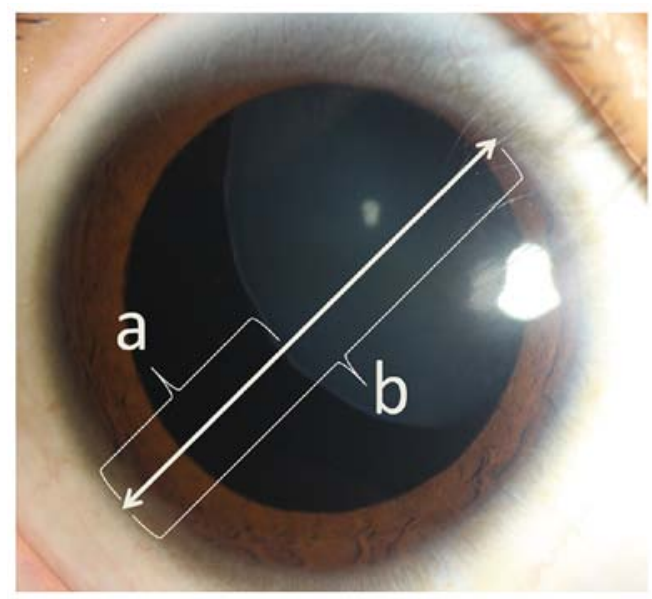

Figure 1. Analysis of the degree of lens dislocation. (a) The degree of lens dislocation was defined by the ratio of the distance from the lens edge to the pupil edge and (b) the length of the white to white corneal diameter (i.e., the horizontal distance between the borders of the corneal limbus).

position. Exclusion criteria included the following: i) Previous intraocular surgery; ii) lens dislocation or cataract caused by head trauma, ocular trauma or surgery; and iii) the presence of inflammatory or infectious eye diseases, glaucoma, or use of topical or systemic anti-inflammatory or anti-infectious agents prior to screening. Aqueous humor samples were collected during clear lens extraction or cataract surgery. A total of 17 CEL patients with 21 eyes and $12 \mathrm{CC}$ patients with 17 eyes were selected for the study, in order to deduce whether the TGF 32 and MMP levels were related to the severity of the lens dislocation in patients with CEL.

Ethics. This research was performed in accordance with The Declaration of Helsinki and was approved by the Institutional Review Board at the Zhongshan Ophthalmic Center, Sun Yat-sen University of Medicine. Written informed consent was obtained from each of the 6 adult subjects, and from the legal guardians of the 23 children, in accordance with The Declaration of Helsinki. All participants provided informed consent for the publication of their data, including images and examination results.

Analysis of the degree of lens dislocation. The degree of lens dislocation was defined by the ratio of the distance from the lens edge to the pupil edge (a) and the length of the white to white corneal diameter (i.e. the horizontal distance between the borders of the corneal limbus) (b) (Fig. 1). This was assessed on anterior segment images from the hospital database of patients with CEL. All the pupils of the patients were pharmacologically dilated with $0.1 \mathrm{ml} 0.5 \%$ tropicamide drops $30 \mathrm{~min}$ before examination. Subsequently, two ophthalmologists and one non-ophthalmic physician assessed the images.

Surgical technique. A single experienced surgeon (DYZ) performed the CEL or CC operations in all cases. Topical $0.3 \%$ ofloxacin eye drop was applied four times each day at $0.1 \mathrm{ml}$ each time, for 3 days prior to surgery. According to standard procedures, none of the patients was in receipt of steroids prior to surgery. 
Table I. Demographic characteristics of 29 patients (comprising 38 eyes in total) in the CEL and CC groups.

\begin{tabular}{lcc}
\hline Characteristic & CEL group & CC group \\
\hline Total no. of subjects (no. of eyes) & $17(21)$ & $12(17)$ \\
Age, years; mean \pm SD (range) & $12.76 \pm 9.37(5-32)$ & $6.82 \pm 9.18(1-32)$ \\
Sex, M/F & $11 / 6$ & $6 / 6$ \\
Tricuspid prolapse, $\mathrm{n}$ & 1 & - \\
Tricuspid incompetence & 4 & - \\
Aorto-sinus dilatation & 6 & - \\
Ascending aorta extension & 1 & - \\
Patent oval foramen & 1 & - \\
Ventriculus sinister diastolic function decrease & 1 & - \\
Without heart disease & 3 \\
\hline
\end{tabular}

CEL, congenital ectopia lentis; $\mathrm{CC}$, congenital cataract; $\mathrm{M}$, male; F, female.

Aqueous humor sampling. In the CEL and CC groups, the primary incision was made under sterile conditions, and undiluted aqueous humor samples $(0.1-0.2 \mathrm{ml})$ were collected into a 30-gauge needle on a tuberculin microsyringe. The samples were immediately frozen, and stored at $-80^{\circ} \mathrm{C}$ until measurements were made. All samples were collected during the year 2016, and stored for 2-3 months under identical conditions.

Multiplex analysis of cytokines in the aqueous humor. All samples were assessed for the total protein levels of TGF $\beta 1$, TGF $\beta 2$, TGF 33 and MMP-1, -2, -3, -7, -8, -9, -10, -12 and -13 using the Luminex system (Luminex $\mathrm{xMAP}^{\circledR}$ technology; Bio-Rad Laboratories, Inc.) and commercially available Bio-Plex Pro ${ }^{\mathrm{TM}}$ Human MMP (catalog number: 171AM001M, Bio-Rad Laboratories, Inc.) and TGF $\beta$ (catalog number: 171W4001M, Bio-Rad Laboratories, Inc.) assays. Each sample was measured twice. The amount (in $\mathrm{pg} / \mathrm{ml}$ ) of TGF $\beta / \mathrm{MMPs}$ present was quantified from the standard curve of each measurement. The same aqueous humor sample was measured in each plate as an internal control.

Statistical analysis. Every experiment was repeated twice. Statistical analysis was performed using SPSS 13.0 software for Windows (SPSS, Inc.). Some of the data values, which were not normally distributed, were analyzed using the Kolmogorov-Smirnov test, and the results are shown as the median and range (25th and 75 th percentiles) for continuous variables under these conditions, including the expression levels of TGF $\beta / M M P$. The mean \pm SD was evaluated for normally distributed continuous variables, such as the age of the patients. A nonparametric test (Mann-Whitney $U$ test) was used to compare abnormally distributed values of TGF $\beta /$ MMPs among the different groups between males and females. The proportions (percentages) of the qualitative variable of sex were analyzed using Pearson's $\chi^{2}$ test. The Spearman correlation coefficient method was used to analyze the correlation between TGF $\beta /$ MMPs and the degree of lens dislocation, or between TGF $\beta /$ MMPs and the age of the patients. $\mathrm{P}<0.05$ was considered to indicate a statistically significant difference.

\section{Results}

Demographic characteristics of 29 patients (38 eyes in total). Aqueous humor samples were obtained from 38 eyes from 29 subjects. A total of $17 \mathrm{CEL}$ patients with 21 eyes (aged 12.76 \pm 9.37 years) and $12 \mathrm{CC}$ patients with 17 eyes (aged $6.82 \pm 9.18$ years) were randomized in the present study (Table I). No statistically significant differences in either sex distribution or age were observed between these two groups. Furthermore, the 17 CEL patients were analyzed via standard echocardiography, and the presence of tricuspid incompetence and aorto-sinus dilatation was identified in $23 \%$ (4/17) and $35 \%(6 / 17)$ of the enrolled subjects, respectively; tricuspid prolapse, ascending aorta extension, patent oval foramen and ventriculus sinister diastolic function decrease were identified in $5 \%(1 / 17)$ respectively. Only for 3 of the patients were no apparent abnormalities identified in terms of cardiac architecture and function. These patients in the CEL group had no other ocular diseases, such as CC or other congenital anterior segment malformations, except for the abnormal lens position.

Levels of TGF $\beta 1,-2$ and -3 . The difference between the TGF $\beta 2$ levels in the CEL and CC groups was identified to be statistically significant $(\mathrm{P}<0.001)$. The level of TGF $\beta 2$ in the $\mathrm{CEL}$ patients was $855.19(744.33,1,009.24) \mathrm{pg} / \mathrm{ml}$, whereas it was $557.08(438.24,692.71) \mathrm{pg} / \mathrm{ml}$ in the CC patients $(\mathrm{P}<0.001)$. However, the differences in the levels of TGF $\beta 1$ and TGF $\beta 3$ in the two groups were not revealed to be statistically significant (Table II and Fig. 2).

Levels of MMP1,-2,-3,-7,-8,-9,-10,-12 and -13. MMP-1 could not be detected in the majority of the aqueous humor samples in the two groups. The differences identified for MMP-2, -3, $-7,-10,-12$ and -13 in the two groups did not reach the level of statistical significance (Table II and Fig. 3). The Mann-Whitney $\mathrm{U}$ test demonstrated that the levels of MMP-2 and MMP-10 in the aqueous humor from the patients with CEL were higher compared with those from the patients with $\mathrm{CC}$, although, again, this did not reach the level of statistical significance $(\mathrm{P}=0.325$ and $\mathrm{P}=0.386$, respectively). However, the levels of 


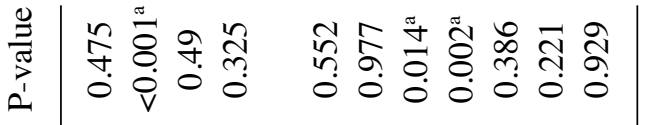

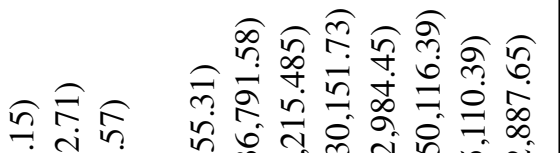

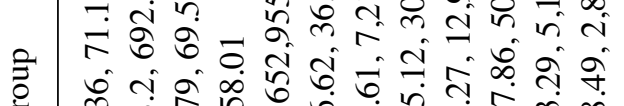

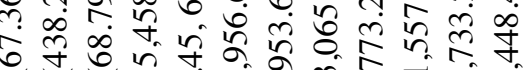
to 0 光

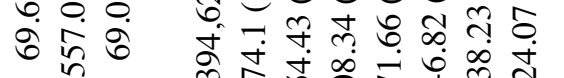

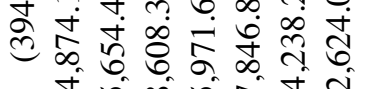
ते in कित

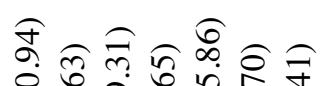

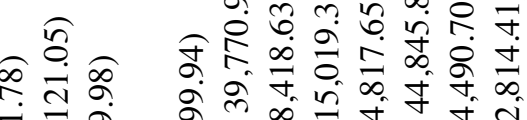

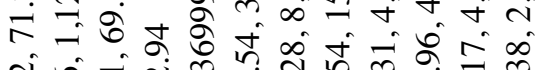

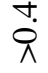
ชิ क

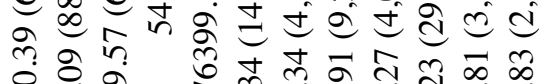
ले $\hat{\imath}$ in

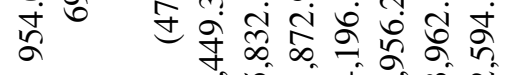
ते हो से ले ले

กิ $\widehat{\sigma} \widehat{\sigma} \widehat{\sigma} \widehat{\sigma} \widehat{\sigma} \widehat{\sigma} \widehat{\infty}$

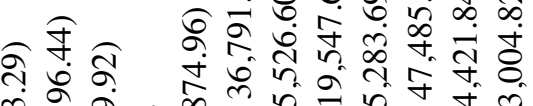
लें के गें

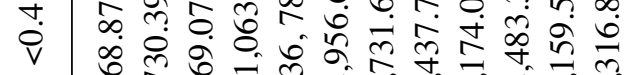
包

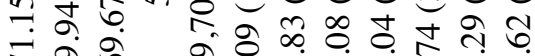

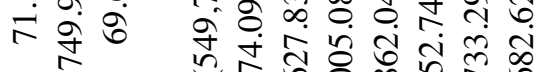

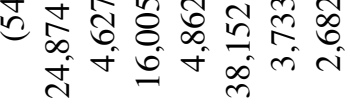

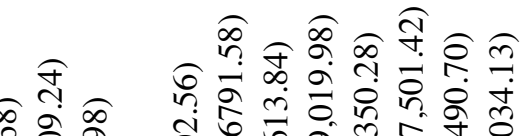

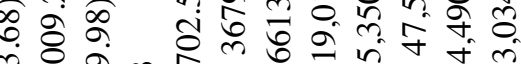
m -1 के ชं mं $\infty$ m 0 क m

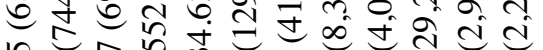

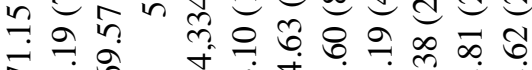

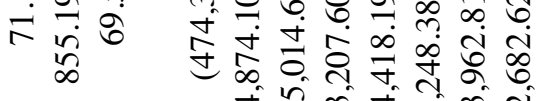
ते जि

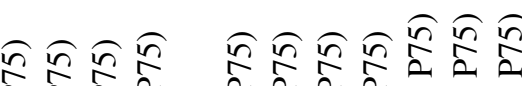

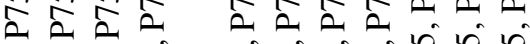

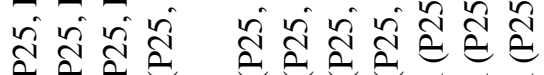




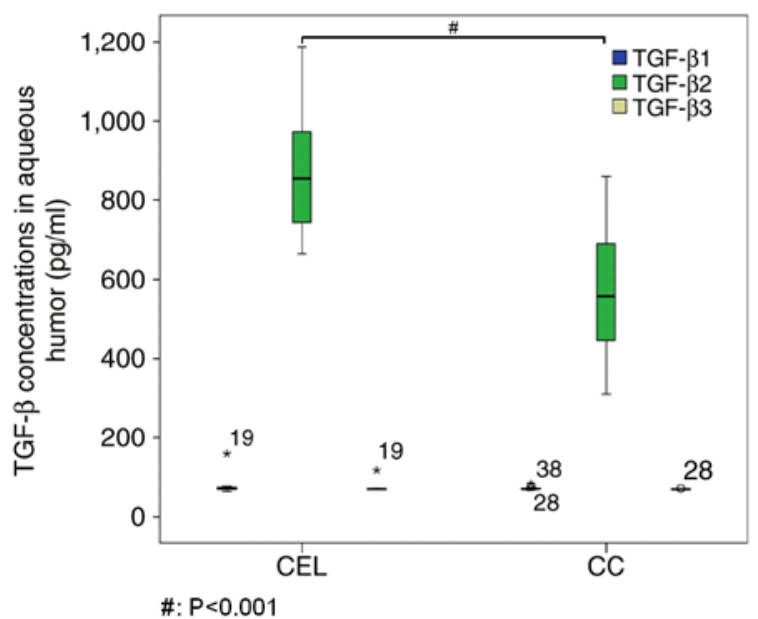

Figure 2. Aqueous humor TGF $\beta$ concentrations in patients with CEL and CC. TGF $\beta 1,2$ and 3 levels in the aqueous humor from 29 patients (38 eyes) in the CEL and CC groups were measured with Luminex xMAP ${ }^{\circledR}$ Technology by using commercially available Bio-Plex Pro $^{\mathrm{TM}}$ Human TGF $\beta$ assays. The Mann-Whitney U test demonstrated that the difference in the TGF- $\beta 2$ level in the two groups was statistically significant. (TGF- $\beta 2$ : ${ }^{~} \mathrm{P}<0.001$ ). The differences in TGF $\beta 1$ and TGF $\beta 3$ levels in the two groups were not statistically significant. TGF $\beta$, transforming growth factor $\beta$; CEL, congenital ectopia lentis; $\mathrm{CC}$, congenital cataract.

MMP-8 and MMP-9 in the aqueous humor of patients with CEL were significantly lower compared with those in the CC patients ( $\mathrm{P}=0.014$ and $\mathrm{P}=0.002$; Table II and Fig. 3).

Relationship between TGF $\beta / M M P$ s and the degree of lens dislocation in the CEL group. The Spearman correlation test revealed that there was a significant positive correlation between the TGF 32 level and the degree of lens dislocation $\left(\mathrm{r}^{2}=0.379, \mathrm{P}=0.003\right.$; Fig. 4). By contrast, no significant correlation was identified between the degree of lens dislocation and the levels of TGF $\beta 1$ and $\beta 3 /$ MMP- $2,-3,-7,-8,-9,-10,-12$ and -13 (Table III; TGF $\beta 1, \mathrm{P}=0.263$; TGF $33, \mathrm{P}=0.571$; MMP-2, $\mathrm{P}=0.238$; MMP-3, $\mathrm{P}=0.98 ; \mathrm{MMP}-7$; $\mathrm{P}=0.989$; MMP-8; $\mathrm{P}=0.552$; MMP-9, $\mathrm{P}=0.638$; MMP-10, $\mathrm{P}=0.726$; MMP-12, $\mathrm{P}=0.812$; and $\mathrm{MMP}-13, \mathrm{P}=0.853$ ).

Relationship between TGF $/ M M P$ s and age in the CEL and $C C$ groups. The Spearman correlation test revealed that TGF $\beta 2$ was positively correlated with age $\left(r^{2}=0.298, \mathrm{P}<0.001\right.$; Fig. 5).

However, the correlation identified between age and the levels of TGF $\beta 1$ and $\beta 3$, and MMP-2, $-3,-7,-8,-9,-10,-12$ and -13 did not reach the level of statistical significance (Table III; TGF 31 , $\mathrm{P}=0.592$; TGF 33 , $\mathrm{P}=0.547$; MMP-2, $\mathrm{P}=0.56$; MMP-3, $\mathrm{P}=0.597$; MMP-7, $\mathrm{P}=0.736$; MMP-8, $\mathrm{P}=0.079$; MMP-9, $\mathrm{P}=0.178 ; \mathrm{MMP}-10, \mathrm{P}=0.453 ; \mathrm{MMP}-12, \mathrm{P}=0.232 ;$ and MMP-13, $\mathrm{P}=0.085$ ).

\section{Discussion}

To the best of the authors' knowledge, the present study is the first to confirm that the expression levels of TGF 32 in the aqueous humor of patients with CEL is associated with the severity of ectopia lentis, suggesting the important role of TGF $\beta$ and MMPs in the pathological process of CEL.
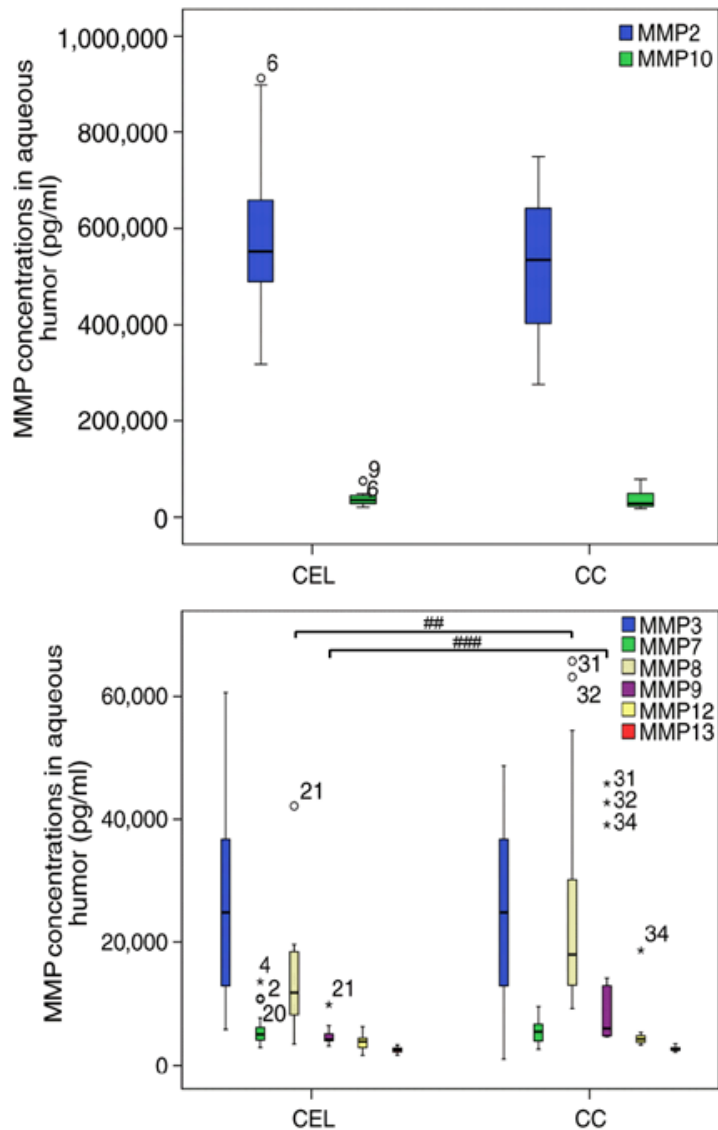

\#: $\mathrm{P}=0.014$

\#\#: $\mathrm{P}=0.002$

Figure 3. Aqueous humor MMP levels in patients with CEL and CC. MMPs levels in the aqueous humor from 29 patients (38 eyes) in the CEL and CC groups were measured with Luminex xMAP ${ }^{\circledR}$ Technology by using commercially available Bio-Plex Pro ${ }^{\mathrm{TM}}$ Human MMP assays. The Mann-Whitney $\mathrm{U}$ test demonstrated that the levels of MMP-2 and MMP-10 in the aqueous humor in the patients with CEL were higher compared with those in the patients with $\mathrm{CC}$, although, this did not reach the level of statistical significance $(\mathrm{P}=0.325$ and $\mathrm{P}=0.386$, respectively). However, the levels of MMP-8 and MMP-9 in the aqueous humor of patients with CEL were significantly lower compared with those in the CC patients (MMP-8: ${ }^{\# \#} \mathrm{P}=0.014$ and MMP-9: $\left.{ }^{\# \#} \mathrm{P}=0.002\right)$. The differences in MMP-2, $-3,-7,-10,-12$ and -13 in the two groups were not statistically significant. However, MMP-1 could not be detected in the aqueous humor samples in either group. MMP, matrix metalloproteinase; CEL, congenital ectopia lentis; $\mathrm{CC}$, congenital cataract.

MFS is characterized as a hereditary disorder with various symptoms, including skeletal, cardiovascular and ocular systems (20). CEL is one of the most commonly identified ocular disorders identified in people with MFS. It is well-recognized that reduced or mutant forms of fibrillin 1 , which induces increased levels of TGF $\beta$ activation, is the precise factor that results in the different clinical features (13). Furthermore, the abnormal homeostasis resulting from overexpression of MMP-2 and MMP-9 leads to a slow deterioration of both the elastin fibers and other components of the ECM (21). The aforementioned reports established that TGF $\beta$ signaling is able to accelerate the progression of aneurysms and pneumothorax in patients diagnosed with MFS. Therefore, the present hypothesis was that TGF $\beta$ signaling may also drive ectopia lentis.

To validate this hypothesis, multiplex bead immunoassays were performed to confirm the levels of TGF $\beta$ and MMPs in 
Table III. Association between the levels of TGF $/$ MMPs and degree of lens dislocation variable in CEL group and also association between the levels of TGF $\beta / M M P s$ and age in CEL and CC groups.

\begin{tabular}{|c|c|c|c|c|}
\hline & \multicolumn{2}{|c|}{$\begin{array}{l}\text { Degree of lens } \\
\text { dislocation variable }\end{array}$} & \multicolumn{2}{|c|}{ Age } \\
\hline & $\mathrm{R}$ & P-value & $\mathrm{R}$ & P-value \\
\hline TGF $\beta 1$ & 0.014 & 0.263 & 0.008 & 0.592 \\
\hline TGF $\beta 2$ & 0.379 & 0.003 & 0.298 & $<0.001$ \\
\hline TGF $\beta 3$ & 0.017 & 0.571 & 0.01 & 0.547 \\
\hline MMP2 & 0.086 & 0.238 & 0.01 & 0.56 \\
\hline MMP3 & 0.000 & 0.98 & 0.008 & 0.597 \\
\hline MMP7 & 0.000 & 0.989 & 0.003 & 0.736 \\
\hline MMP8 & 0.019 & 0.552 & 0.083 & 0.079 \\
\hline MMP9 & 0.012 & 0.638 & 0.05 & 0.178 \\
\hline MMP10 & 0.007 & 0.726 & 0.016 & 0.453 \\
\hline MMP12 & 0.002 & 0.812 & 0.039 & 0.232 \\
\hline MMP13 & 0.003 & 0.853 & 0.08 & 0.085 \\
\hline
\end{tabular}

TGF $\beta$, transforming growth factor $\beta$; MMP, matrix metalloproteinase; CEL, congenital ectopia lentis; CC, congenital cataract.

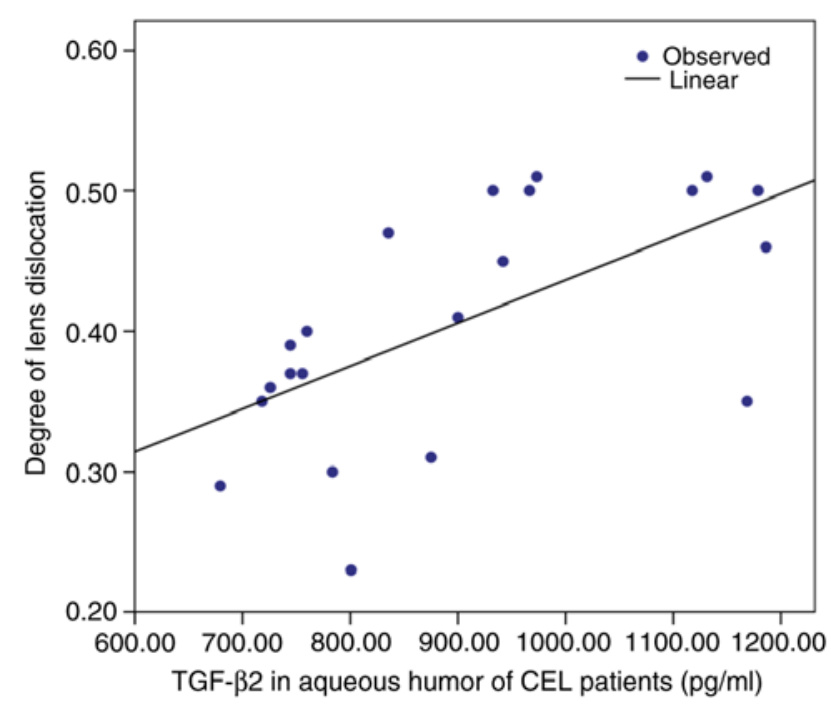

Figure 4. Association between the TGF $\beta 2$ concentration and the degree of lens dislocation in the CEL group. TGF $\beta 2$ levels in the aqueous humor from 17 patients ( 21 eyes) with CEL were measured with Luminex xMAP Technology by using commercially available Bio-Plex Pro $^{\text {TM }}$ Human TGF $\beta$ assays. The Spearman correlation test revealed that there was a significant positive correlation between the TGF $\beta 2$ level and the degree of lens dislocation $\left(r^{2}=0.379 ; P=0.003\right)$. TGF $\beta$, transforming growth factor $\beta$; CEL, congenital ectopia lentis.

the aqueous humor. It was identified that the concentration of TGF $\beta 2$ was significantly increased in CEL patients compared with the control groups, and a significant association was identified between the levels of TGF $\beta 2$ in the aqueous humor of patients with CEL and the severity of CEL, indicating that the signaling pathways mediated by TGF $\beta$ serve a crucial role in the architecture and function of the zonular fibers.

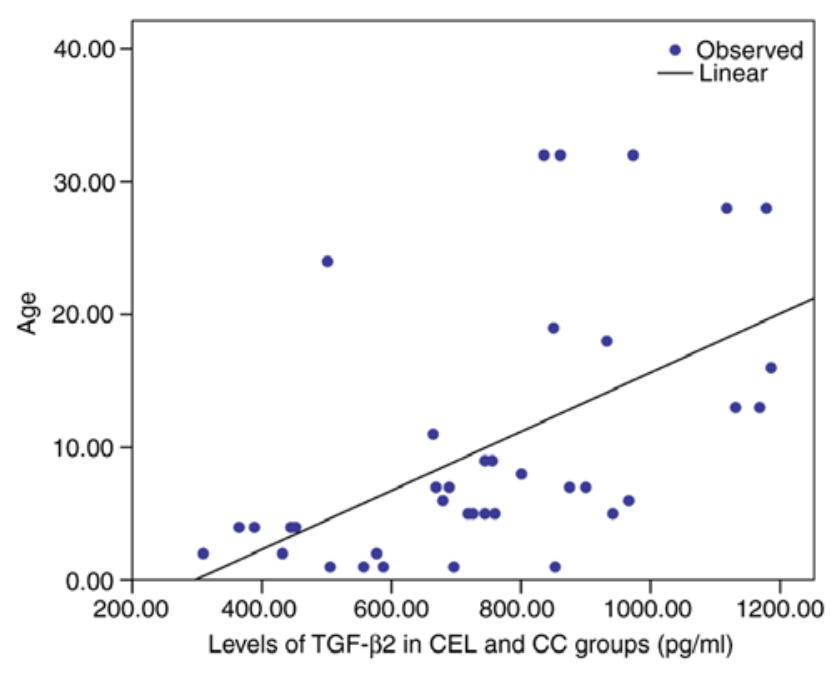

Figure 5. Correlation between TGF $\beta 2$ concentration and age in patients with CEL and CC. MMP and TGF 32 levels in the aqueous humor from 29 patients (38 eyes) in the CEL and CC groups were measured with Luminex $\mathrm{XMAP}^{\circledR}$ Technology by using commercially available Bio-Plex Pro $^{\mathrm{TM}}$ Human MMP and TGF $\beta$ assays. Spearman correlation test showed that TGF $\beta 2$ were positively correlated with the age $\left(\mathrm{r}^{2}=0.298 ; \mathrm{P}<0.001\right)$. No significant correlation was found between the age and TGF $\beta 1$ and 3, MMP-2, -3, -7, -8, -9, -10, -12 and 13 levels. MMP, matrix metalloproteinase; TGF $\beta$, transforming growth factor $\beta$; CEL, congenital ectopia lentis; $\mathrm{CC}$, congenital cataract.

It has been previously shown that TGF $\beta$ is secreted as a large latent complex that consists of TGF $\beta$, its binding protein and latency-associated peptide (22). Fibrillin 1, which is characterized as an isomer of latent TGF $\beta$ binding proteins, is able to specifically bind to the TGF $\beta$ latent complex. TGF $\beta$ signaling is initiated by binding of TGF $\beta$ to its receptors, activating its downstream signaling cascades by releasing the mature TGF $\beta$ that is regulated by proteases or MMPs (23).

Previously, researchers have focused on the canonical and non-canonical TGF $\beta$ signaling pathways, due to the important roles they serve in aneurysms (16). On the basis of their results, the present hypothesis was that a deficiency of fibrillin 1 in the patients with CEL may inhibit matrix sequestration of the large latent complex of TGF $\beta$, subsequently rendering this cytokine more prone to activation. Furthermore, TGF $\beta$ signaling may be involved in the regulation of MMPs, causing CEL.

TGF $\beta$ is classified as an upstream mediator of matrix metabolism, and MMPs are considered important factors in the progression of aneurysms in patients with MFS (24). However, the role of TGF $\beta /$ MMPs in ectopia lentis progression is yet to be properly elucidated. The present study revealed that aqueous humor samples from patients with CEL exhibited levels of MMP-2 and -10 that were higher compared with those in patients with CC, although the level of statistical significance was not attained. Interestingly, the levels of MMP- 8 and MMP-9 in the aqueous humor of the CEL patients were significantly lower compared with those in the CC patients. Since no healthy persons were included in the present study as a control group, it was not possible to conclude that the levels of MMPs in the aqueous humor of the CEL patients were higher than those normally identified in the general population. However, the levels of MMP-8 and MMP-9 in the aqueous humor of CC patients were significantly higher, suggesting that MMPs may be an unknown factor involved in CC. 
MMPs and their tissue inhibitors are all expressed in the aqueous humor with or without age-associated cataracts (25). Upon a review of the relevant literature, no studies reporting that MMPs in the aqueous humor are relevant to $\mathrm{CC}$ were identified. Some findings have indicated that lens cells may synthesize MMPs upon certain injuries, such as cataract surgery or oxidative stress (26-28).

It has been documented that TGF $\beta$ drives anterior subcapsular cataract formation due to the increasing levels of MMP-2 and MMP-9, thereby promoting the development of posterior capsule opacification (29-33). Researchers have previously observed that the level of MMP-9 activity varies in different types of cataracts (34). It has been demonstrated that the level of MMP-9 activity in lens epithelial cells increases with the age of patients with age-associated cataract (34). However, MMP proteins are not only secreted by ciliary non-pigment epithelial cells in the aqueous humor (35). It has been reported that scleral fibroblasts (36), uveal melanocytes (37), ciliary muscle cells (38-40), trabecular cells $(41,42)$ and retinal pigment epithelial cells (43-45) are able to produce MMPs and secrete or exchange them to the aqueous humor. The changes in the MMP expression levels may result from the homeostatic mechanism of various cells in the aqueous humor. Therefore, the levels of MMPs in the aqueous humor of CEL patients may or may not serve a key role in the disintegration of zonular fibers, and further studies are required to explore the role of MMPs in ectopia lentis.

A limitation of the present study was that these samples were not compared with age-matched control healthy persons, due to ethical reasons. On the other hand, active inflammatory factors in the aqueous humor in the eyes of cadavers are degraded slowly, because the protein in the aqueous humor of cadavers is easy to dissolve and inactivate. Due to the age factor, $\mathrm{CC}$ patients were included to provide a study contrast. Besides, the only accurate information about congenital ectopia lentis available was a general diagnosis, with no genetic information due to economic or technical reasons. Therefore, it was not possible to make the diagnosis of MFS. The small number of patients enrolled also limited the results, and further studies are required that include a larger number of subjects.

In conclusion, the findings in the present study indicated that TGF $\beta$ signaling activation may promote the progression of CEL. These findings may support targeting TGF $\beta$ signaling as a potential therapy to prevent the complications in patients with MFS that arise from CEL.

\section{Acknowledgements}

Not applicable.

\section{Funding}

The present study was supported by the Science and Technology Planning Project of Guangdong Province (grant no. 2014A020212106) and the National Natural Science Foundation (grant no. NSFC 81873673).

\section{Availability of data and materials}

The datasets used and/or analyzed during the present study are available from the corresponding author on reasonable request.

\section{Authors' contributions}

QC, BX, GJ and DZ conceived and designed the experiments. $\mathrm{BX}$ performed the experiments. BZ, MC and $\mathrm{KW}$ analyzed the data. JiL, YW, JuL and YZ contributed reagents/materials/analysis tools, and helped perform the experiments and acquired data. QC, BX, GJ and CAY wrote the paper. CAY analyzed and interpreted the patient data regarding the standard echocardiography and was a major contributor in writing the manuscript.

\section{Ethics approval and consent to participate}

This research was performed in accordance with The Declaration of Helsinki and was approved by the Institutional Review Board at the Zhongshan Ophthalmic Center, Sun Yat-sen University of Medicine. Written informed consent was obtained from each of the 6 adult subjects, and from the legal guardians of the 23 children, in accordance with The Declaration of Helsinki.

\section{Patient consent for publication}

All participants provided informed consent for the publication of their data, including images and examination results.

\section{Competing interests}

The authors declare that they have no competing interests.

\section{References}

1. Dietz H: Marfan syndrome. In: Adam MP, Ardinger HH, Pagon RA, Wallace SE, Bean LJH, Stephens K and Amemiya A (eds). GeneReviews. University of Washington, Seattle, Bookshelf ID: NBK1335, 2017.

2. Shi Y and Massagué J: Mechanisms of TGF-beta signaling from cell membrane to the nucleus. Cell 113: 685-700, 2003.

3. Tandon A, Tovey JC, Sharma A, Gupta R and Mohan RR: Role of transforming growth factor Beta in corneal function, biology and pathology. Curr Mol Med 10: 565-578, 2010.

4. Pervan CL, Lautz JD, Blitzer AL, Langert KA and Stubbs EB Jr: Rho GTPase signaling promotes constitutive expression and release of TGF- $\beta 2$ by human trabecular meshwork cells. Exp Eye Res 146: 95-102, 2016.

5. Ochiai $\mathrm{Y}$ and Ochiai $\mathrm{H}$ : Higher concentration of transforming growth factor-beta in aqueous humor of glaucomatous eyes and diabetic eyes. Jpn J Ophthalmol 46: 249-253, 2002.

6. Habashi JP, Judge DP, Holm TM, Cohn RD, Loeys BL, Cooper TK, Myers L, Klein EC, Liu G, Calvi C, et al: Losartan, an AT1 antagonist, prevents aortic aneurysm in a mouse model of Marfan syndrome. Science 312: 117-121, 2006.

7. Neptune ER, Frischmeyer PA, Arking DE, Myers L, Bunton TE, Gayraud B, Ramirez F, Sakai LY and Dietz HC: Dysregulation of TGF-beta activation contributes to pathogenesis in Marfan syndrome. Nat Genet 33: 407-411, 2003.

8. Isogai Z, Ono RN, Ushiro S, Keene DR, Chen Y, Mazzieri R, Charbonneau NL, Reinhardt DP, Rifkin DB and Sakai LY: Latent transforming growth factor beta-binding protein 1 interacts with fibrillin and is a microfibril-associated protein. J Biol Chem 278: 2750-2757, 2003

9. Hynes RO: The extracellular matrix: Not just pretty fibrils. Science 326: 1216-1219, 2009.

10. Gomez D, Coyet A, Ollivier V, Jeunemaitre X, Jondeau G, Michel JB and Vranckx R: Epigenetic control of vascular smooth muscle cells in Marfan and non-Marfan thoracic aortic aneurysms. Cardiovasc Res 89: 446-456, 2011.

11. Mu Y, Gudey SK and Landström M: Non-Smad signaling pathways. Cell Tissue Res 347: 11-20, 2012.

12. Kang JS, Liu C and Derynck R: New regulatory mechanisms of TGF-beta receptor function. Trends Cell Biol 19: 385-394, 2009. 
13. Derynck R and Zhang YE: Smad-dependent and Smadindependent pathways in TGF-beta family signalling. Nature 425: 577-584, 2003.

14. Lee MK, Pardoux C, Hall MC, Lee PS, Warburton D, Qing J, Smith SM and Derynck R: TGF-beta activates Erk MAP kinase signalling through direct phosphorylation of ShcA. EMBO J 26: 3957-3967, 2007.

15. Yamashita $\mathrm{M}$, Fatyol $\mathrm{K}$, Jin $\mathrm{C}$, Wang $\mathrm{X}$, Liu Z and Zhang YE. TRAF6 mediates Smad-independent activation of JNK and p38 by TGF-beta. Mol Cell 31: 918-924, 2008.

16. Holm TM, Habashi JP, Doyle JJ, Bedja D, Chen Y, van Erp C, Lindsay ME, Kim D, Schoenhoff F, Cohn RD, et al: Noncanonical TGF $\beta$ signaling contributes to aortic aneurysm progression in Marfan syndrome mice. Science 332: 358-361, 2011.

17. Gomes LR, Terra LF, Wailemann RA, Labriola L and Sogayar MC: TGF- $\beta 1$ modulates the homeostasis between MMPs and MMP inhibitors through p38 MAPK and ERK1/2 in highly invasive breast cancer cells. BMC cancer 12: 26, 2012.

18. Chung AW, Au-Yeung K, Sandor GG, Judge DP, Dietz HC and van-Breemen C: Loss of elastic fiber integrity and reduction of vascular smooth muscle contraction resulting from the upregulated activities of matrix metalloproteinase-2 and -9 in the thoracic aortic aneurysm in Marfan syndrome. Circ Res 101: 512-522, 2007.

19. Wang Y, Ait-Oufella H, Herbin O, Bonnin P, Ramkhelawon B Taleb S, Huang J, Offenstadt G, Combadière C, Rénia L, et al: TGF-beta activity protects against inflammatory aortic aneurysm progression and complications in angiotensin II-infused mice. J Clin Invest 120: 422-432, 2010.

20. Haneline M and Lewkovich GN: A narrative review of pathophysiological mechanisms associated with cervical artery dissection. J Can Chiropr Assoc 51: 146-157, 2007.

21. Nataatmadja $\mathbf{M}$, West $\mathbf{J}$ and West $\mathbf{M}$ : Overexpression of transforming growth factor-beta is associated with increased hyaluronan content and impairment of repair in Marfan syndrome aortic aneurysm. Circulation 114 (1 Suppl): I371-I377, 2006.

22. Chaudhry SS, Cain SA, Morgan A, Dallas SL, Shuttleworth CA and Kielty CM: Fibrillin-1 regulates the bioavailability of TGFbeta1. J Cell Biol 176: 355-367, 2007.

23. ten-Dijke P and Arthur HM: Extracellular control of TGFbeta signalling in vascular development and disease. Nat Rev Mol Cell Biol 8: 857-869, 2007.

24. Nataatmadja M, West M, West J, Summers K, Walker P, Nagata M and Watanabe T: Abnormal extracellular matrix protein transport associated with increased apoptosis of vascular smooth muscle cells in marfan syndrome and bicuspid aortic valve thoracic aortic aneurysm. Circulation 108 (Suppl 1): II329-II334, 2003.

25. Di-Girolamo N, Verma MJ, McCluskey PJ, Lloyd A and Wakefield D: Increased matrix metalloproteinases in the aqueous humor of patients and experimental animals with uveitis. Curr Eye Res 15: 1060-1068, 1996.

26. Sachdev NH, Di-Girolamo N, Nolan TM, McCluskey PJ, Wakefield D and Coroneo MT: Matrix metalloproteinases and tissue inhibitors of matrix metalloproteinases in the human lens: Implications for cortical cataract formation. Invest Ophthalmol Vis Sci 45: 4075-4082, 2004

27. Tamiya S, Wormstone IM, Marcantonio JM, Gavrilovic J and Duncan G: Induction of matrix metalloproteinases 2 and 9 following stress to the lens. Exp Eye Res 71: 591-597, 2000.

28. Seomun Y, Kim J, Lee EH and Joo CK: Overexpression of matrix metalloproteinase-2 mediates phenotypic transformation of lens epithelial cells. Biochem J 358: 41-48, 2001.

29. Dwivedi DJ, Pino G, Banh A, Nathu Z, Howchin D, Margetts P, Sivak JG and West-Mays JA: Matrix metalloproteinase inhibitors suppress transforming growth factor-beta-induced subcapsular cataract formation. Am J Pathol 168: 69-79, 2006

30. de-Iongh RU, Wederell E, Lovicu FJ and McAvoy JW: Transforming growth factor-beta-induced epithelial-mesenchymal transition in the lens: A model for cataract formation. Cells Tissues Organs 179: 43-55. 2005.
31. Li J, Tang $X$ and Chen X: Comparative effects of TGF- $\beta 2 / S m a d 2$ and TGF- $\beta 2 /$ Smad 3 signaling pathways on proliferation, migration, and extracellular matrix production in a human lens cell line. Exp Eye Res 92: 173-179, 2011.

32. Sinpitaksakul SN, Pimkhaokham A, Sanchavanakit N and Pavasant P: TGF-beta1 induced MMP-9 expression in HNSCC cell lines via Smad/MLCK pathway. Biochem Biophys Res Commun 371: 713-718, 2008

33. Yao J, Yang W, Liu Y, Sun YX and Jiang Q: Dexamethasone inhibits TGF- 32 -induced migration of human lens epithelial cells: implications for posterior capsule opacification prevention. Mol Med Rep 5: 1509-1513, 2012.

34. Alapure BV, Praveen MR, Gajjar D, Vasavada AR, Rajkumar S and Johar K: Matrix metalloproteinase-9 activity in human lens epithelial cells of cortical, posterior subcapsular, and nuclear cataracts. J Cataract Refract Surg 34: 2063-2067, 2008.

35. Rösch S, Ramer R, Brune K and Hinz B: R(+)-methanandamide and other cannabinoids induce the expression of cyclooxygenase-2 and matrix metalloproteinases in human nonpigmented ciliary epithelial cells. J Pharmacol Exp Ther 316: 1219-1228, 2006.

36. McBrien NA, Lawlor P and Gentle A: Scleral remodeling during the development of and recovery from axial myopia in the tree shrew. Invest Ophthalmol Vis Sci 41: 3713-3719, 2000.

37. Chu SC, Hu DN, Yang SF, Yang PY, Hsieh YS, Huang SM, Yu G and McCormick SA: Uveal melanocytes produce matrix metalloproteinases-2 and -9 in vitro. Pigment Cell Res 17: 636-642, 2004.

38. Weinreb RN and Lindsey JD: Metalloproteinase gene transcription in human ciliary muscle cells with latanoprost. Invest Ophthalmol Vis Sci 43: 716-722, 2002.

39. Oh DJ, Martin JL, Williams AJ, Peck RE, Pokorny C, Russell P, Birk DE and Rhee DJ: Analysis of expression of matrix metalloproteinases and tissue inhibitors of metalloproteinases in human ciliary body after latanoprost. Invest Ophthalmol Vis Sci 47: 953-963, 2006

40. Lan YQ, Zhang C, Xiao JH, Zhuo YH, Guo H, Peng W and Ge J: Suppression of IkappaBalpha increases the expression of matrix metalloproteinase-2 in human ciliary muscle cells. Mol Vis 15: 1977-1987, 2009.

41. Alexander JP, Samples JR, Van-Buskirk EM and Acott TS: Expression of matrix metalloproteinases and inhibitor by human trabecular meshwork. Invest Ophthalmol Vis Sci 32: 172-180, 1991.

42. Pang IH, Hellberg PE, Fleenor DL, Jacobson N and Clark AF: Expression of matrix metalloproteinases and their inhibitors in human trabecular meshwork cells. Invest Ophthalmol Vis Sci 44: 3485-3493, 2003.

43. Bandyopadhyay M and Rohrer B: Matrix metalloproteinase activity creates pro-angiogenic environment in primary human retinal pigment epithelial cells exposed to complement. Invest Ophthalmol Vis Sci 53: 1953-1961, 2012.

44. Zeng A, Zeng S, Cheng Y and Xiao Q: Modulation of matrix metalloproteinase and TIMP-1 expression by TGF-beta1 in cultured human RPE cells. J Huazhong Univ Sci Technolog Med Sci 26: 363-365, 2006.

45. Christian PG, Harkin DG, Rayner $C$ and Schmid KL: Comparative effects of posterior eye cup tissues from myopic and hyperopic chick eyes on cultured scleral fibroblasts. Exp Eye Res 107: 11-20, 2013.

This work is licensed under a Creative Commons Attribution-NonCommercial-NoDerivatives 4.0 International (CC BY-NC-ND 4.0) License. 